\title{
Genome-Wide Scanning Reveals Complex Etiology of Oculo-Auriculo-Vertebral Spectrum
}

\author{
Xue-shuang Huang, ${ }^{1,2, *}$ Xin Li,, 3 Can Tan, ${ }^{2}$ Ling Xiao, ${ }^{2}$ Hai-ou Jiang, \\ Shu-fang Zhang, ${ }^{4}$ Dun-mei Wang ${ }^{3}$ and Jian-xiang Zhang ${ }^{2,5}$

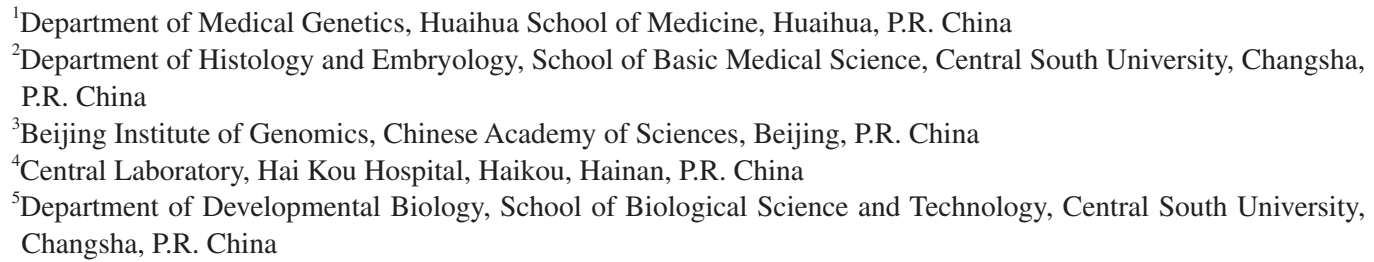

Oculo-auriculo-vertebral spectrum (OAVS) is a common developmental disorder involving first and second pharyngeal arches. Although some family cases and such patients showing chromosomal aberrations suggest that OAVS have a genetic basis, no consistent genetic defects have been recorded at present time. Thus, we conducted genetic studies of a three-generation family with five OAVS patients to identify a causative variant for OAVS. Cytogenetic studies revealed those family members had a normal karyotype and no causative mutations were founded in SALL1 and TCOF1, which known to be responsible for two other syndromes that have clinical overlapping with OAVS. Genotyping with commercially available BeadChips was performed on 13 individuals in the same family, showing no significant difference between the affected and normal members in terms of copy number variations (CNVs) in either number or size and no definitive causative CNV. A total of 8,224 informative autosomal SNPs that are evenly distributed throughout the genome were selected for both parametric and non-parametric linkage analysis. Significant negative LOD scores were obtained for the reported OAVS locus, providing further evidence for genetic heterogeneity of this complex disorder. The highest LOD score of 1.60 was noted on chromosome 15q26.2-q26.3 showing a potential linkage to this locus. The variable phenotypes of the affected members and the failure to identify a causative variant indicate that a complex etiology may be present even in a consanguineous family, which makes it more challenging to ascertain the cause of OAVS in further analysis.

Keywords: copy number variation; epibulbar dermoid; facial asymmetry; variable phenotype; vertebral anomaly Tohoku J. Exp. Med., 2010, 222 (4), 311-318. (C) 2010 Tohoku University Medical Press

Oculo-auriculo-vertebral spectrum (OAVS, OMIM 164210), also known as Goldenhar syndrome and hemifacial microsomia (HFM), is a defect of the first and second branchial arch leading to abnormal morphogenesis of the facial structures. It has a wide phenotypic variation involving microtia or preauricular tags, hemifacial microsomia, and dermoid and vertebral anomalies. There is no consistent cause responsible for this condition, thus no diagnostic criteria have been established. However, it is generally accepted that multiple accessory tags with a preauricular/ mandibular distribution is a more common characteristic, and they are an important diagnostic clue in recognizing this syndrome (Engiz et al. 2007). Tasse et al. (2005) suggested that relatives of typically affected OAVS patients, who show minor signs of the syndrome such as preauricular tags/pits, exhibit mild forms of the disorder.

The incidence of OAVS has been estimated to be 1/5,600 1/20,000 (Grabb 1965; Melnick 1980; Stoll et al. 1984). Most cases are sporadic and the causes are largely unclear. Maternal use of medications (Jacobsson and Granstrom 1997; Johnston and Bronsky 1995) and maternal diabetes (Wang et al. 2002) contribute to infants with OAVS, which suggests that nongenetic factors play a role in the development of OAVS. Nevertheless, chromosomal aberrations (Engiz et al. 2007; Balci et al. 2006; Choong et al. 2003; Descartes 2006; Josifova et al. 2004; Ala-Mello et al. 2008; Xu et al. 2008; Rooryck et al. 2009) and the identification of several families with autosomal dominant (Tsai

Received October 14, 2010; revision accepted for publication November 17, 2010. doi: 10.1620/tjem.222.311

*These authors contributed equally to this work.

Correspondence: Jian-xiang Zhang, Department of Developmental Biology, School of Biological Science and Technology, Central South University, Changsha 410013, P.R. China.

e-mail: jxzh99@yahoo.com.cn 
and Tsai 1993; Stoll et al. 1998; Tasse et al. 2007; Goodin et al. 2009; Vendramini-Pittoli and Kokitsu-Nakata 2009) or recessive inheritance (Kaye et al. 1992) indicate that OAVS has a hereditary basis.

To date, no specific gene has been identified for OAVS. Although a linkage with chromosome 14q32.1 has been demonstrated in one family with hemifacial microsomia compatible with the autosomal dominant model, the presumed candidate gene mutation was excluded in that family and in 120 sporadic cases (Kelberman et al. 2001). Therefore, studies of additional families are of importance to the identification of the loci involved. Fischer et al. (2006) found abnormal BAPX1 expression in a significant number of OAVS patients and suggested that epigenetic disregulation of BAPX1 might play a role in the etiology of OAVS. In addition, a few patients showing clinical overlap with OAVS had mutations in sal-like 1 (SALL1) (Kohlhase et al. 1999; Keegan et al. 2001; Kosaki et al. 2007) or Treacher Collins-Franceschetti syndrome 1 (TCOF1) (Su et al. 2007), the genes responsible for most cases of Townes-Brocks syndrome [OMIM 107480] and Treacher Collins syndrome [OMIM 154500], respectively, which are also associated with first and second branchial arch anomalies. Even though cytogenetic alterations have been associated with many cases of OAVS, most of the chromosomal aberrations are patient-specific, except that chromosome 5p (Choong et al. 2003; Descartes 2006; Josifova et al. 2004; Ala-Mello et al. 2008) and 22q (Balci et al. 2006; Xu et al. 2008; Derbent et al. 2003; Digilio et al. 2009) have been implicated in a number of cases.

Recently developed whole-genome array-based technologies can detect genomic structural variation at a much higher resolution than conventional cytogenetic methods. Therefore, these techniques have become a useful way to reveal copy number variations (CNVs) associated with complex disorders such as autism (Sebat et al. 2007) and amyotrophic lateral sclerosis (Blauw et al. 2008). Because of the elusive cause of OAVS and the substantial contribution of CNVs to genetic susceptibility of complex disorders, a genome-wide survey of genomic aberrations, including common and rare variants, might be used instead of a traditional genetic analysis. Recently, array studies indeed have confirmed the presence of microdeletions in some sporadic cases with features of OAVS (Ala-Mello et al. 2008; Xu et al. 2008; Rooryck et al. 2009; Huang et al. 2010). However, to our knowledge, a family-based association between CNVs and the OAVS phenotype has not been investigated.

Therefore, here we describe a three-generation family including five OAVS patients showing an apparent genetic defect, and reported our results of karyotype analysis and mutation screening of SALL1 and TCOF1. Furthermore, we performed genome-wide genotyping using high-density arrays to identify the underlying genetic cause and potential candidate loci for OAVS.

\section{Methods}

\section{Patients and family}

This study protocol has been reviewed and approved by the Research Ethics Committee of Central South University. The subjects and/or their parents gave informed consent and anonymity has been preserved.

The pedigree is shown in Fig. 1. The proband (patient 34, Fig. 2 ) is the second child of healthy, non-consanguineous parents of Chinese origin, and was born after 39 weeks gestation by vaginal delivery. At birth, she was noted to have two left-sided preauricular tags and one epibulbar dermoid in her left eye. We performed further physical examinations when she was 14 years old. Except for a shortened pendulous palate and intumescent tonsil on the right side, no further apparent abnormalities were noted. Patient 35 is the younger sister of patient 34 and was born at 38 weeks of gestation. She was presented for clinical examination at the age of 9 years. Two preauricular tags on her right side and one on her left side were noted. She had mild micrognathia with malocclusion, which impaired her pronunciation. In addition, hypertelorism, epicanthi, astigmatism, and Strabism were present. Patient 33, the brother of the two affected sisters, died 21 days after birth. There was no record of his birth information, and his parents were unable to provide any clinical phenotype except that he died of heart disease and multiple preauricular tags were present on both sides. Patient 21 is the uncle of the two affected girls. He underwent diagnostic evaluation at the age of 42 years. He had mild facial asymmetry with a smaller left face and three preauricular tags lining his right side. Patient 32, a 12-year-old boy, is the second son of patient 21. At his first presentation, one preauricular tag with a stenotic external auditory canal and invaginated drumhead on the left side were noted. At a subsequent clinical examination, we found the presence of epicanthi, a shortened pendulous palate and mild facial asymmetry. Radiographs showed right lateral fusion and

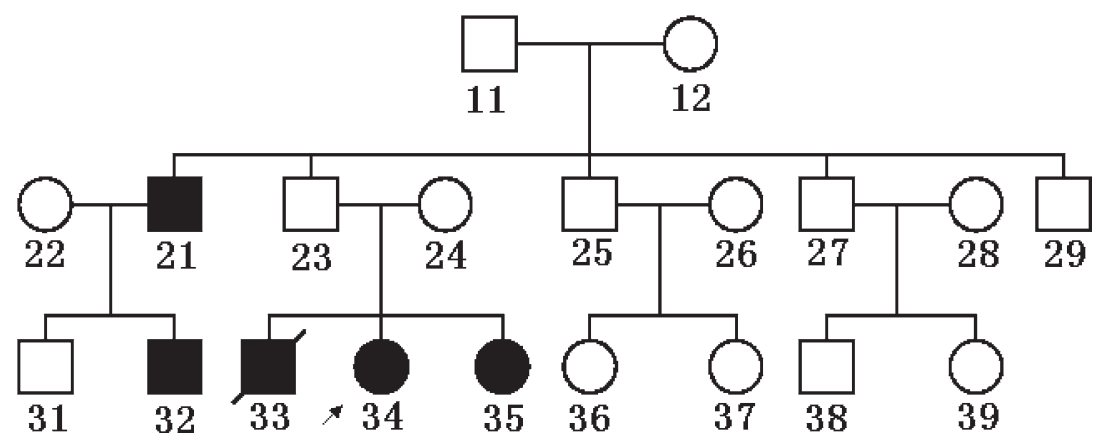

Fig. 1. Pedigree of the OAVS family. The proband (34) is indicated by an arrow. Squares indicate males and circles indicate females, black symbols indicate affected individuals and crossed lines denote deceased individuals. 

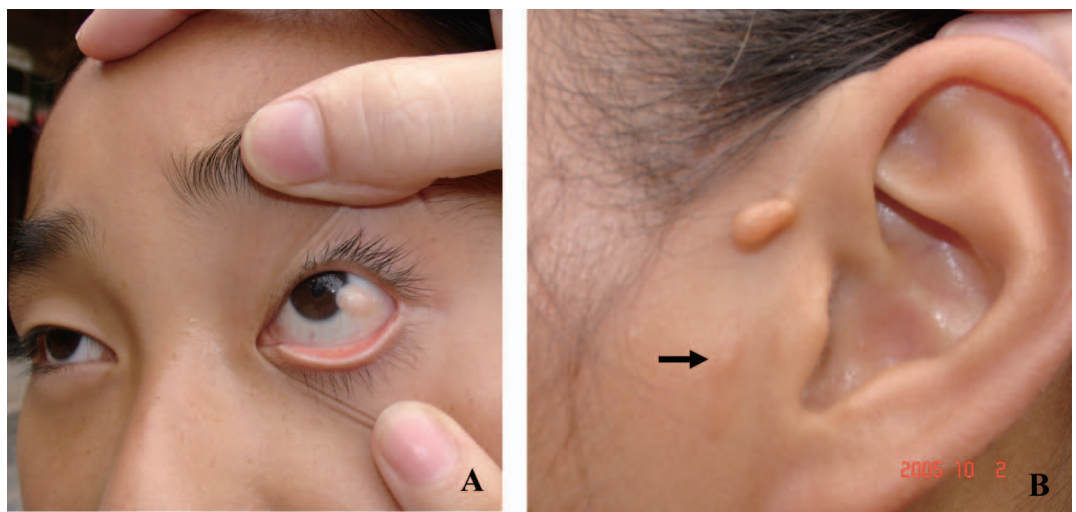

Fig. 2. Facial phenotype of the proband. Facial phenotype of the proband (patient 34) showing one epibulbar dermoid in her left eye (A). Two preauricular tags on the left side (B), of which the small one is unnoticeable but palpable (arrow).

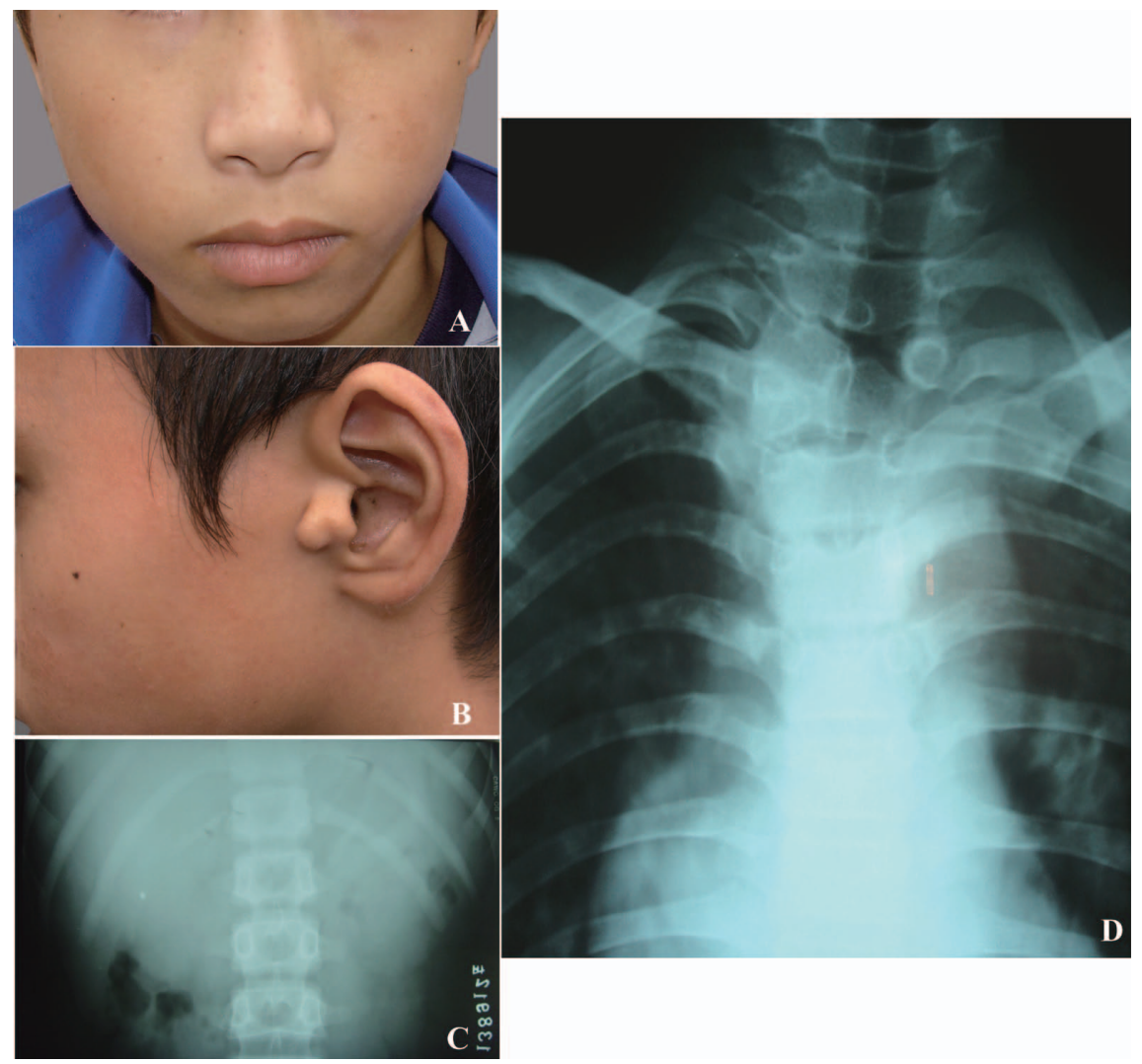

Fig. 3. Photographs of patient 32. Photographs of patient 32 showing a smaller left face (A), one preauricular tag and narrow external auditory on the left side (B). Radiograph of the vertebral column showing the T2-T3 hemivertebrae and evident scoliosis of the thoracic spine (D). The $12^{\text {th }}$ rib on the right side was very short and small (C).

left lateral absence of the T2-T3 vertebrae. The 2nd and 3rd ribs on the left side were very short and small and formed a hemivertebrae, and there was scoliosis of the thoracic spine. The 12 th rib on the right side was also very short (about $2 \mathrm{~cm}$ ) and there was an absence of the demilune at the inferior costal head, which gave the rib a spoon-like appearance, and the sternocostal joint was very small (Fig. 3). Radiological examination on patients 34,35 and 21 showed no apparent abnormality. All of the affected living family members showed normal psychomotor development and intelligence, and their heart, liver, spleen and kidneys were normal by ultrasonographic examina- tion. History of exposure to teratogenic substances or of pertinent maternal illnesses and consanguinity were denied. The birth measurements were not available due to the fact that those babies were born with the help of a midwife in the village rather than delivered in a well organized hospital.

Subjects 11 and 23 exhibited mild facial asymmetry, but ear anomalies and other features were absent. Thus, the diagnostic criteria were not fulfilled and the diagnosis of these subjects is inconclusive. The remaining family members (subjects $12,25,27,31$, and 37) and the spouses (subjects 22, 24, and 26) did not show any remarkable 
anomalies.

Cytogenetic analysis

All four live patients underwent chromosome analysis on peripheral blood lymphocytes at a 550-band level using standard procedures. Attention was paid especially to chromosomes 5p13-pter and 22q11-13.31.

\section{DNA sampling and mutation detection of SALL1 and TCOF1}

Whole-blood genomic DNA of 13 family members (11, 12, 21, $22,23,24,25,27,31,32,34,35$, and 37) was obtained using a genomic DNA purification kit. Mutation screening of SALL1 and TCOF1 was performed as previously described (Kohlhase et al. 1999; Thiel et al. 2005; Botzenhart et al. 2007).

\section{Genome-wide scanning}

Genomic DNA of 13 family members was genotyped with Illumina Human 370 Genotyping BeadChip (Illumina Inc., San Diego, CA), which contains 317,000 TagSNPs and 52,000 non-polymorphic markers to specifically target almost 14,000 known copy number variants (CNVs) with a mean spatial resolution of approximately 7.7 $\mathrm{kb}$. All procedures were done according to the manufacturer's protocol. In brief, $250 \mathrm{ng}$ genomic DNA was amplified, fragmented and hybridized to the array. The products were fluorescently labeled and scanned with the Illumina Beadstation scanner (Illumina Inc.) and image data were analyzed using Beadstudio v3.3 genotyping software (Illumina Inc.).

Copy number analysis was performed using the data derived from the Human 370 BeadChips with cnvPartition 1.2.1 and the Genome Viewer tool. CNV regions detected in patients were only considered if they involved at least three consecutive probes.

Inconsistencies with the genetic data concerning major gene inheritance were investigated with Pedcheck (O'Connell and Weeks 1998). Questionable double recombinants were identified with the genotype error option of the linkage software Merlin (Abecasis et al. 2002). A total of 8,224 informative autosomal SNPs, evenly distrib- uted through the genome with an average spacing of $350 \mathrm{~Kb}$, were selected for linkage analysis. Both multipoint parametric and nonparametric linkage analyses were performed using the linkage software Merlin. Parametric linkage analysis was performed under an autosomal-dominant model with the following parameters: a risk allele frequency of 0.0001 and different penetrances such as 0.8 and 0.99 for genotypes with 1 or 2 copies of the risk allele (Kelberman et al. 2001).

\section{Results}

G-banding (500 band level) was peformed on the proband and showed a normal 46, XX karyotype (Fig. 4). The same analysis which was carried out on the other patients in the family also revealed no abnormalities.

In total, we identified $153 \mathrm{CNVs}$ in the family. The number of CNVs in each affected member ranged from 8 to $18($ mean $=12.50$; S.D. $=4.20)$ and the size of these CNVs ranged from $646 \mathrm{bp}$ to $1,167,295 \mathrm{bp}(\mathrm{M}=66.4 \mathrm{~kb}, \mathrm{Q}=85.4$ $\mathrm{kb})$. By contrast, the number of CNVs in each unaffected member ranged from 8 to $17($ mean $=11.44$, s.D. $=3.57)$ and the size of these CNVs ranged from $646 \mathrm{bp}$ to $1,807,334$ bp $(\mathrm{M}=59.0 \mathrm{~kb}, \mathrm{Q}=86.6 \mathrm{~kb})$. There were no significant differences between the CNV number ( $p=0.649, t$-test) or CNV size ( $p=0.304$, Wilcoxon Mann-Whitney test) between the affected and unaffected individuals. To identify the common CNVs in the patients with OAVS, we investigated the distribution of all $153 \mathrm{CNVs}$ and found $8 \mathrm{CNVs}$ present in at least two patients (Table 1). Of the $8 \mathrm{CNVs}, 3$ (in 3q26.1, 4q13.2, and 6p21.32) were present in all four patients but were also present in most of the unaffected members, and thus were unlikely to be associated with the disease in this family. The CNV in 9p11.2 was noted in three patients (patients 21,34, and 35) and two suspected patients (subjects 11 and 23). However, this CNV was also

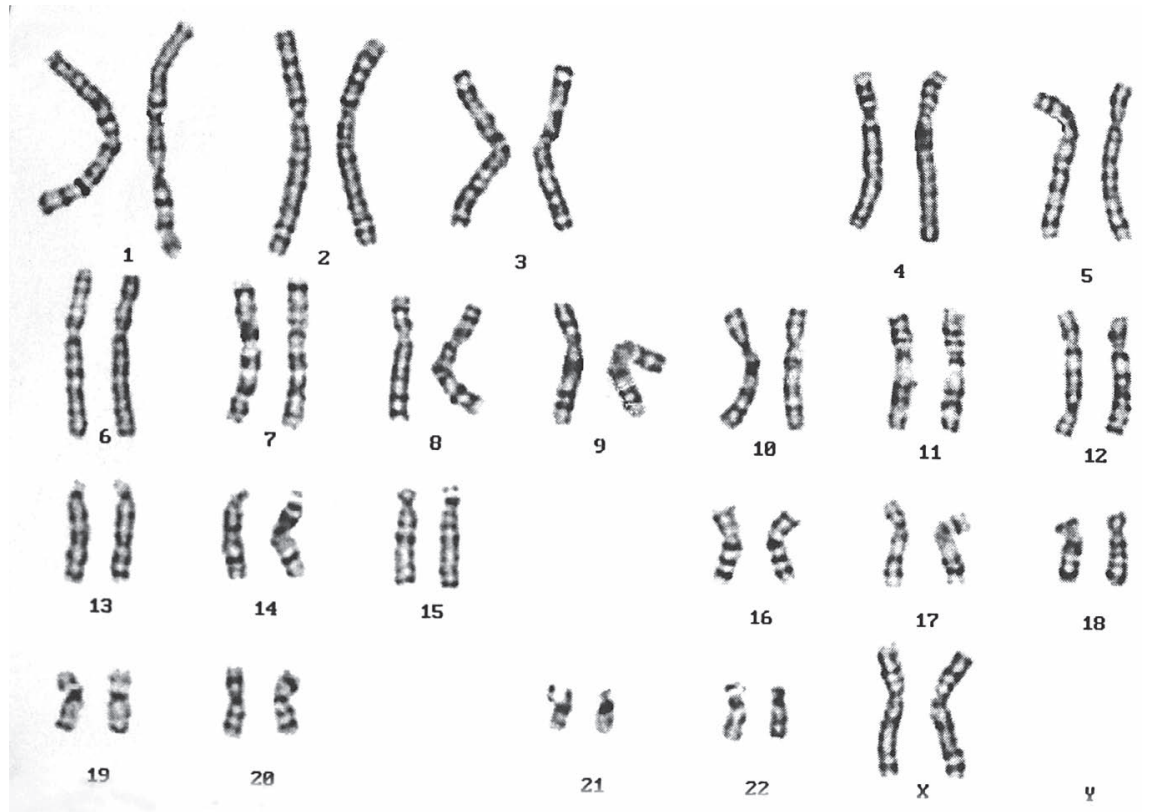

Fig. 4. The karyotype of the proband. G-banding (500 band level) showed a normal 46, XX karyotype. 
Table 1. Eight CNVs detected in at least two patients.

\begin{tabular}{|c|c|c|c|c|c|c|}
\hline Cytoband & Position & Size & $\begin{array}{l}\mathrm{CNV} \\
\text { Value }\end{array}$ & individual & DGV data & Genes \\
\hline \multirow[t]{2}{*}{$1 \mathrm{q} 21.3$} & $149,611,365 . .149,674,317$ & 62,952 & 3 & 32,23 & Gain & $\begin{array}{l}\text { SELENBP1 } \\
\text { PSMB4 }\end{array}$ \\
\hline & $149,614,370 . .149,674,317$ & 59,948 & 3 & 35 & & POG2 \\
\hline $3 q 26.1$ & $164,004,033 . .164,101,579$ & 97,546 & 0 & $\begin{array}{l}11,12, \mathbf{2 1}, 22,23,25 \\
27,31, \mathbf{3 2}, \mathbf{3 4}, \mathbf{3 5}, 37\end{array}$ & Gain/loss & 0 \\
\hline \multirow[t]{3}{*}{$4 q 13.2$} & $69,064,675 . .69,163,188$ & 98,513 & 0 & $\begin{array}{c}11,22,23,27, \mathbf{3 2}, \mathbf{3 4} \\
\mathbf{3 5}\end{array}$ & Gain/loss & $\begin{array}{l}\text { UGT2B17 } \\
\text { UGT2B15 }\end{array}$ \\
\hline & $69,064,675 . .69,163,188$ & 98,513 & 1 & 25 & & \\
\hline & $69,064,675 . .69,195,500$ & 130,825 & 0 & 24 & & \\
\hline \multirow[t]{3}{*}{$6 \mathrm{p} 21.32$} & $32,563,460 . .32,593,470$ & 30,010 & 0 & $\mathbf{2 1}, 22,25, \mathbf{3 4}, 37$ & Gain/loss & HLA-DRB5 \\
\hline & $32,563,460 . .32,597,079$ & 33,619 & 0 & $11,31, \mathbf{3 2}$ & & \\
\hline & $32,574,137 . .32,593,470$ & 19,334 & 0 & 35 & & \\
\hline \multirow[t]{6}{*}{$9 \mathrm{p} 11.2$} & $43,515,795 . .43,616,717$ & 100,922 & 0 & 27 & Gain/loss & AK024257 \\
\hline & $43,515,795 . .43,674,189$ & 158,394 & 0 & 35 & & AK054645 \\
\hline & $43,515,795 . .43,720,352$ & 204,557 & 0 & 23 & & KGFLP1 \\
\hline & $43,515,795 . .44,683,090$ & $1,167,295$ & 0 & 34 & & BC108270 \\
\hline & $43,515,795 . .44,683,090$ & $1,167,295$ & 1 & 21 & & \\
\hline & $43,570,503 . .44,683,090$ & $1,112,587$ & 0 & 11 & & \\
\hline \multirow[t]{3}{*}{$10 q 11.22$} & $46,189,908 . .47,218,918$ & $1,029,010$ & 1 & 34 & Gain/loss & ВC065722 \\
\hline & $46,710,573 . .47,773,683$ & $1,063,110$ & 3 & 32 & & $\begin{array}{l}\text { SYT15 } \\
\text { KIAA0514 }\end{array}$ \\
\hline & $46,751,993 . .47211888$ & 459,895 & 1 & 24 & & $\begin{array}{l}\text { PPYR1 } \\
\text { ANXA8 }\end{array}$ \\
\hline \multirow[t]{3}{*}{$11 \mathrm{q} 11$} & $55,124,465 . .55,209,499$ & 85,034 & 0 & $11,24,34$ & Gain/loss & OR4S2 \\
\hline & $55,124,465 . .55,209,499$ & 85,034 & 1 & 35 & & OR4C6 \\
\hline & $55,130,549 . .55,209,499$ & 78,950 & 1 & 37 & & \\
\hline $13 q 31.1$ & $83,001,708 . .83,055,928$ & 54,220 & 1 & $12, \mathbf{2 1}, 27, \mathbf{3 5}$ & Gain/loss & 0 \\
\hline
\end{tabular}

Summary of the eight CNVs detected in at least two patients (shown in bold) in the family, and the presence of each CNV in DGV data. The genes in each $\mathrm{CNV}$ region are also listed.

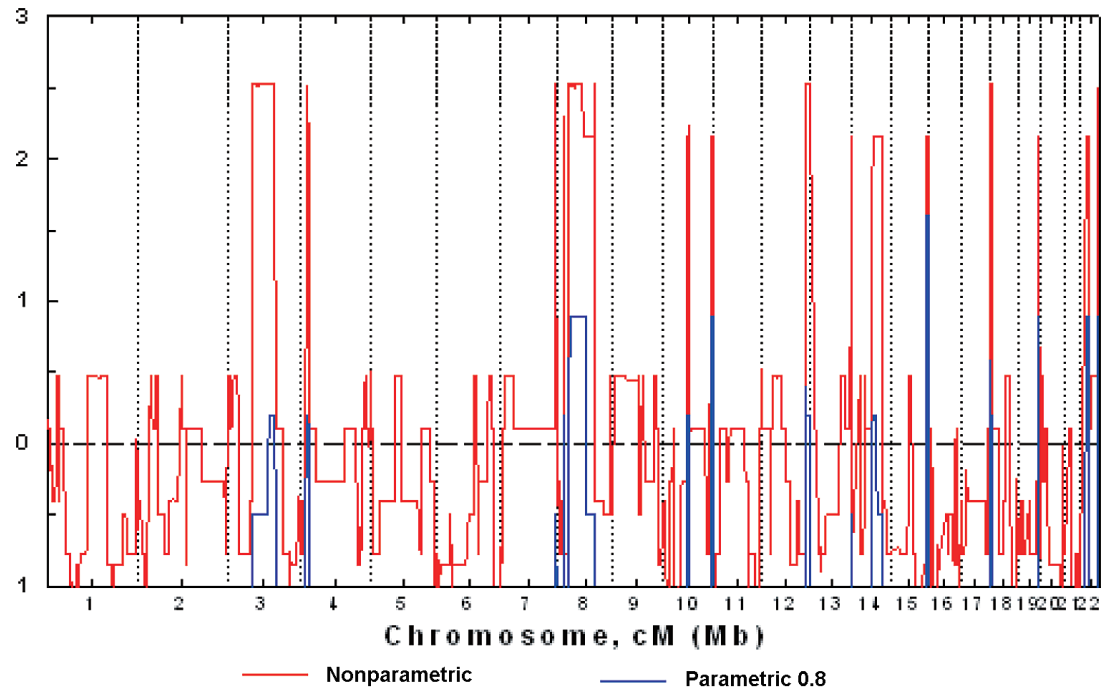

Fig. 5. The results of linkage analysis. Whole genome linkage analysis with 8,224 informative autosomal SNPs. Blue line and red line show the results of parametricand and non-parametric linkage analysis, respectively. 
seen in one normal sibling (subject 27), but not in patient 32 , and it had different boundary and copy number states $(0$ or 1 copy) among individuals. Other $4 \mathrm{CNVs}$ (in 1q21.3, $10 q 11.22$, 11q11, and 13q31.1) were also not exclusively present in the affected individuals. Thus, no clear copy number variation was identified responsible for this disorder in the family.

Parametric linkage analysis assuming different penetrances did not identify any logarithm of the odds (LOD) score higher than 2. A maximum LOD score of 1.60 was noted on chromosome 15 at 96.154-99.881 Mb (15q26.2q26.3), and none of the other genomic regions showed LOD scores greater than 1. Nonparametric linkage (NPL) revealed several genomic regions such as $4 \mathrm{p} 15.32,7 \mathrm{q} 36.2$, $12 \mathrm{q} 24.31$, and $18 \mathrm{p} 11.3$ with a NPL score greater than 2 besides chromosome 15q26.2-q26.3 (NPL $=2.2, p=0.02)$ (Fig. 5). Significantly negative LOD scores $(<-2)$ were obtained on chromosome 14 at $88.9-95.5 \mathrm{Mb}$, excluding the linkage to chromosome $14 \mathrm{q} 32.1$.

\section{Discussion}

The clinical findings of the five patients in this study are extremely variable, including ocular anomalies, tags, vertebral defects and facial dysplasia. All of the cases presented multiple preauricular tags. Mild hemifacial microsomia was noted in two affected family members (patients 21 and 32), while epibulbar dermoid, vertebral anomalies, and micrognathia were only noted in patients 34, 32 and 35, respectively. Although each patient has milder manifestations when compared with sporadic cases, their diagnosis as OAVS is most likely in this family (Tasse et al. 2005), which supports the extremely heterogeneous phenotype of this disorder even within siblings (Tsai and Tsai 1993; Stoll et al. 1998; Tasse et al. 2007; Goodin et al. 2009; Vendramini-Pittoli and Kokitsu-Nakata 2009).

All four of the living patients with OAVS were analyzed by high-resolution G-banding, and negative results were obtained. In addition, mutational screening for SALL1 and TCOF1 were negative, indicating that the OAVS in this family is unlikely to be caused by a gross chromosomal abnormality or as a result of Townes-Brocks syndromes or Treacher Collins.

Based on the recently demonstrated role of structural variants in the etiology of complex diseases (Sebat et al. 2007; Blauw et al. 2008) and the presence of microdeletions in some sporadic cases with features of OAVS (Ala-Mello et al. 2008; Xu et al. 2008; Rooryck et al. 2009; Huang et al. 2010), we attempted to use high-density SNP-genotype data to determine the structural variation in this family, and found no significant differences of the CNV number and size between the affected and unaffected individuals. Although five CNVs (in 1q21.3, 9p11.2, 10q11.22, 11q11, and $13 \mathrm{q} 31.1$ ) were present in patients at higher ratios, they were also seen in unaffected family members. Normal ratios are reported in the Database of Genomic Variants (DGV, http://projects.tcag.ca/variation). Thus, copy number analysis did not reveal a clear genomic cause for this disorder. Indeed, several lines of evidence have indicated that CNVs are common in populations, some of which may have serious phenotypic consequences (Khaja et al. 2006; Redon et al. 2006). Therefore, deciding whether or not a copy number change is pathological or polymorphic can be challenging in complex traits (Beleza-Meireles et al. 2008).

Linkage analysis using 8,224 informative SNP markers and different parameters showed no significant LOD scores. One peak above 1.5 was encountered using both parametric and nonparametric analysis at $15 q 26.2-q 26.3$, indicating potential linkage according to the standard by Lander and Kruglyak (1995). Linkage to chromosome 14q32.1, the OAVS locus that was mapped in one family by Kelberman et al. (2001), was excluded for significant negative LOD scores $(<-2)$, which provided further evidence for genetic heterogeneity of this complex disorder.

There might be three possible explanations why we could not identify a clear cause responsible for OAVS in this family. First, it might be induced by smaller copy number variants, which may require more advanced technology to detect. Second, the family we studied was too small to obtain a significant linkage interval. Another family with features similar to the patients in this study would help to identify such a locus. Third, the phenotypes of the patients we studied might result from several minor-effect gene variants. Some genes in the regions indicated by this study may directly or indirectly influence the development of the first and second branchial arch leading to abnormal morphogenesis of the facial structures. The genes in these putative regions are worth investigating, and some candidate genes would be selected by functional relevancy and sequenced in all patients to validate this presumption.

In summary, we described a family with OAVS, which was characterized, most likely, by autosomal dominant inheritance with reduced penetrance. In such a case, genetic variants may underlie the cause of the defects. Nevertheless, the variable phenotypes of the affected members and the failure to identify a causative variant up to now suggest that a complex etiology may be present even in a consanguineous family, which makes it a challenging task to identify the cause of OAVS.

\section{Acknowledgments}

We thank the patient and all the subjects for participating in our study and the physicians for referring the patient to us. We also thank Dr. Mary Beth Kirkham, Department of Agronomy and Dr. George H.Liang, Professor Emeritus, Department of Agronomy and Former Chairman, Inter-Departmental Program of Genetics, Kansas State University for polishing the paper. This work was funded by the National Natural Sciences Foundation of China (No. 30671104).

\section{References}

Abecasis, G.R., Cherny, S.S., Cookson, W.O. \& Cardon, L.R. (2002) Merlin-rapid analysis of dense genetic maps using sparse gene flow trees. Nat. Genet., 30, 97-101. 
Ala-Mello, S., Siggberg, L., Knuutila, S., von Koskull, H., Taskinen, M. \& Peippo, M. (2008) Further evidence for a relationship between the $5 \mathrm{p} 15$ chromosome region and the oculoauriculovertebral anomaly. Am. J. Med. Genet. A, 146A, 24902494.

Balci, S., Engiz, O., Yilmaz, Z. \& Baltaci, V. (2006) Partial trisomy $(11 ; 22)$ syndrome with manifestations of Goldenhar sequence due to maternal balanced $\mathrm{t}(11 ; 22)$. Genet. Couns., 17, 281289.

Beleza-Meireles, A., Kockum, I., Yuan, Q.P., Picelli, S., Wetterberg, L., Gustavson, K.H. \& Schalling, M. (2008) Complex aetiology of an apparently Mendelian form of mental retardation. BMC. Med. Genet., 9, 6.

Blauw, H.M., Veldink, J.H., van Es, M.A., van Vught, P.W., Saris, C.G., van der Zwaag, B., Franke, L., Burbach, J.P., Wokke, J.H., Ophoff, R.A. \& van den Berg, L.H. (2008) Copy-number variation in sporadic amyotrophic lateral sclerosis: a genomewide screen. Lancet. Neurol., 7, 319-326.

Botzenhart, E.M., Bartalini, G., Blair, E., Brady, A.F., Elmslie, F., Chong, K.L., Christy, K., Torres-Martinez, W., Danesino, C., Deardorff, M.A., Fryns, J.P., Marlin, S., Garcia-Minaur, S., Hellenbroich, Y., Hay, B.N., Penttinen, M., Shashi, V., Terhal, P., Van Maldergem, L., Whiteford, M.L., Zackai, E. \& Kohlhase, J. (2007) Townes-Brocks syndrome: twenty novel SALL1 mutations in sporadic and familial cases and refinement of the SALL1 hot spot region. Hum. Mutat., 28, 204205.

Choong, Y.F., Watts, P., Little, E. \& Beck, L. (2003) Goldenhar and cri-du-chat syndromes: a contiguous gene deletion syndrome? J. AAPOS, 7, 226-227.

Derbent, M., Yilmaz, Z., Baltaci, V., Saygili, A., Varan, B. \& Tokel, K. (2003) Chromosome 22q11.2 deletion and phenotypic features in 30 patients with conotruncal heart defects. Am. J. Med. Genet. A, 116A, 129-135.

Descartes, M. (2006) Oculoauriculovertebral spectrum with 5p15.33-pter deletion. Clin. Dysmorphol., 15, 153-154.

Digilio, M.C., McDonald-McGinn, D.M., Heike, C., Catania, C., Dallapiccola, B., Marino, B. \& Zackai, E.H. (2009) Three patients with oculo-auriculo-vertebral spectrum and microdeletion 22q11.2. Am. J. Med. Genet. A, 149A, 2860-2864.

Engiz, O., Balci, S., Unsal, M., Ozer, S., Oguz, K.K. \& Aktas, D. (2007) 31 cases with oculoauriculovertebral dysplasia (Goldenhar syndrome): clinical, neuroradiologic, audiologic and cytogenetic findings. Genet. Couns., 18, 277-288.

Fischer, S., Lüdecke, H.J., Wieczorek, D., Böhringer, S., GillessenKaesbach, G. \& Horsthemke, B. (2006) Histone acetylation dependent allelic expression imbalance of BAPX1 in patients with the oculo-auriculo-vertebral spectrum. Hum. Mol. Genet., 15, 581-587.

Goodin, K., Prucka, S., Woolley, A.L., Kohlhase, J., Smith, R.J., Grant, J. \& Robin, N.H. (2009) Familial transmission of oculoauriculovertebral spectrum (Goldenhar syndrome) is not due to mutations in either EYA1 or SALL1. Am. J. Med. Genet. A, 149A, 535-538.

Grabb, W.C. (1965) The first and second branchial arch syndrome. Plast. Reconstr. Surg., 36, 485-508.

Huang, X.S., Xiao, L., Li, X., Xie, Y., Jiang, H.O., Tan, C., Wang, L., Zhang, J.X. (2010) Two neighboring microdeletions of 5 q13.2 in a child with oculo-auriculo-vertebral spectrum. Eur. J. Med. Genet., 53, 153-158.

Jacobsson, C. \& Granstrom, G. (1997) Clinical appearance of spontaneous and induced first and second branchial arch syndromes. Scand. J. Plast. Reconstr. Surg. Hand Surg., 31, 125-136.

Johnston, M.C. \& Bronsky, P.T. (1995) Prenatal craniofacial development: New insights on normal and abnormal mechanisms. Crit. Rev. Oral Biol. Med., 6, 368-422.

Josifova, D.J., Patton, M.A. \& Marks, K. (2004) Oculoauriculovertebral spectrum phenotype caused by an unbalanced $t(5 ; 8)$ (p15.31;p23.1) rearrangement. Clin. Dysmorphol., 13, 151153.

Kaye, C.I., Martin, A.O., Rollnick, B.R., Nagatoshi, K., Israel, J., Hermanoff, M., Tropea, B., Richtsmeier, J.T. \& Morton, N.E. (1992) Oculoauriculovertebral anomaly: segregation analysis. Am. J. Med. Genet., 43, 913-917.

Keegan, C.E., Mulliken, J.B., Wu, B.L. \& Korf, B.R, (2001) Townes-Brocks syndrome versus expanded spectrum hemifacial microsomia: review of eight patients and further evidence of a "hot spot" for mutation in the SALL1 gene. Genet. Med., 3, 310-313.

Kelberman, D., Tyson, J., Chandler, D.C., McInerney, A.M., Slee, J., Albert, D., Aymat, A., Botma, M., Calvert, M., Goldblatt, J., Haan, E.A., Laing, N.G., Lim, J., Malcolm, S., Singer, S.L., Winter, R.M. \& Bitner-Glindzicz, M. (2001) Hemifacial microsomia: progress in understanding the genetic basis of a complex malformation syndrome. Hum. Genet., 109, 638-645.

Khaja, R., Zhang, J., MacDonald, J.R., He, Y., Joseph-George, A.M., Wei, J., Rafiq, M.A., Qian, C., Shago, M., Pantano, L., Aburatani, H., Jones, K., Redon, R., Hurles, M., Armengol, L., Estivill, X., Mural, R.J., Lee, C., Scherer, S.W. \& Feuk, L. (2006) Genome assembly comparison identifies structural variants in the human genome. Nat. Genet., 38, 1413-1418.

Kohlhase, J., Taschner, P.E., Burfeind, P., Pasche, B., Newman, B., Blanck, C., Breuning, M.H., ten Kate, L.P., Maaswinkel-Mooy, P., Mitulla, B., Seidel, J., Kirkpatrick, S.J., Pauli, R.M., Wargowski, D.S., Devriendt, K., Proesmans, W., Gabrielli, O., Coppa, G.V., Wesby-van Swaay, E., Trembath, R.C., Schinzel, A.A., Reardon, W., Seemanova, E. \& Engel, W. (1999) Molecular analysis of SALL1 mutations in Townes-Brocks syndrome. Am. J. Hum. Genet., 64, 435-445.

Kosaki, R., Fujimaru, R., Samejima, H., Yamada, H., Izumi, K., Iijima, K. \& Kosaki, K. (2007) Wide phenotypic variations within a family with SALL1 mutations: Isolated external ear abnormalities to Goldenhar syndrome. Am. J. Med. Genet. A, 143A, 1087-1090.

Lander, E. \& Kruglyak, L. (1995) Genetic dissection of complex traits: guidelines for interpreting and reporting linkage results. Nat. Genet., 11, 241-247.

Melnick, M. (1980) The etiology of external ear malformations and its relation to abnormalities of the middle ear, inner ear, and other organ systems. Birth Defects Orig. Artic. Ser., 16, 303-331.

O'Connell, J.R. \& Weeks, D.E. (1998) PedCheck, a program for identification of genotype incompatibilities in linkage analysis. Am. J. Hum. Genet., 63, 259-266.

Redon, R., Ishikawa, S., Fitch, K.R., Feuk, L., Perry, G.H., Andrews, T.D., Fiegler, H., Shapero, M.H., Carson, A.R., Chen, W., Cho, E.K., Dallaire, S., Freeman, J.L., González, J.R., Gratacòs, M., Huang, J., Kalaitzopoulos, D., Komura, D., MacDonald, J.R., Marshall, C.R., Mei, R., Montgomery, L., Nishimura, K., Okamura, K., Shen, F., Somerville, M.J., Tchinda, J., Valsesia, A., Woodwark, C., Yang, F., Zhang, J., Zerjal, T., Zhang, J., Armengol, L., Conrad, D.F., Estivill, X., Tyler-Smith, C., Carter, N.P., Aburatani, H., Lee, C., Jones, K.W., Scherer, S.W. \& Hurles, M.E. (2006) Global variation in copy number in the human genome. Nature, 444, 444-454.

Rooryck, C., Stef, M., Burgelin, I., Simon, D., Souakri, N., Thambo, J.B., Chateil, J.F., Lacombe, D. \& Arveiler, B. (2009) $2.3 \mathrm{Mb}$ terminal deletion in $12 \mathrm{p} 13.33$ associated with oculoauriculovertebral spectrum and evaluation of WNT5B as a candidate gene. Eur. J. Med. Genet., 52, 446-449.

Sebat, J., Lakshmi, B., Malhotra, D., Troge, J., Lese-Martin, C., Walsh, T., Yamrom, B., Yoon, S., Krasnitz, A., Kendall, J., Leotta, A., Pai, D., Zhang, R., Lee, Y.H., Hicks, J., Spence, S.J., Lee, A.T., Puura, K., Lehtimäki, T., Ledbetter, D., Gregersen, P.K., Bregman, J., Sutcliffe, J.S., Jobanputra, V., Chung, W., Warburton, D., King, M.C., Skuse, D., Geschwind, D.H., Gilliam, T.C., Ye, K. \& Wigler, M. (2007) Strong asso- 
ciation of de novo copy number mutations with autism. Science, 316, 445-449.

Stoll, C., Roth, M.P., Dott, B. \& Bigel, P. (1984) Discordance for skeletal and cardiac defect in monozygotic twins. Acta. Genet. Med. Gemellol (Roma), 33, 501-504.

Stoll, C., Viville, B., Treisser, A. \& Gasser, B. (1998) A family with dominant oculoauriculovertebral spectrum. Am. J. Med. Genet., 78, 345-349.

Su, P.H., Yu, J.S., Chen, J.Y., Chen, S.J., Li, S.Y. \& Chen, H.N. (2007) Mutations and new polymorphic changes in the TCOF1 gene of patients with oculo-auriculo-vertebral spectrum and Treacher-Collins syndrome. Clin. Dysmorphol., 16, 261-267.

Tasse, C., Böhringer, S., Fischer, S., Lüdecke, H.J., Albrecht, B., Horn, D., Janecke, A., Kling, R., König, R., Lorenz, B., Majewski, F., Maeyens, E., Meinecke, P., Mitulla, B., Mohr, C., Preischl, M., Umstadt, H., Kohlhase, J., Gillessen-Kaesbach, G. \& Wieczorek, D. (2005) Oculo-auriculo-vertebral spectrum (OAVS): clinical evaluation and severity scoring of 53 patients and proposal for a new classification. Eur. J. Med. Genet., 48, 397-411.

Tasse, C., Majewski, F., Böhringer, S., Fischer, S., Lüdecke, H.J., Gillessen-Kaesbach, G. \& Wieczorek, D. (2007) A family with autosomal dominant oculo-auriculo-vertebral spectrum. Clin. Dysmorphol., 16, 1-7.

Thiel, C.T., Rosanowski, F., Kohlhase, J., Reis, A. \& Rauch, A. (2005) Exclusion of TCOF1 mutations in a case of bilateral Goldenhar syndrome and one familial case of microtia with meatal atresia. Clin. Dysmorphol., 14, 67-71.

Tsai, F.J. \& Tsai, C.H. (1993) Autosomal dominant inherited oculo-auriculo-vertebral spectrum: report of one family. Zhonghua Min Guo Xiao Er Ke Yi Xиe Hui Za Zhi, 34, 27-31.

Vendramini-Pittoli, S. \& Kokitsu-Nakata, N.M. (2009) Oculoauriculovertebral spectrum: report of nine familial cases with evidence of autosomal dominant inheritance and review of the literature. Clin. Dysmorphol., 18, 67-77.

Wang, R., Martínez-Frías, M.L. \& Graham, J.M. Jr. (2002) Infants of diabetic mothers are at increased risk for the oculo-auriculovertebral sequence: A case-based and case-control approach. $J$. Pediatr., 141, 611-617.

Xu, J., Fan, Y.S. \& Siu, V.M. (2008) A child with features of Goldenhar syndrome and a novel $1.12 \mathrm{Mb}$ deletion in $22 \mathrm{q} 11.2$ by cytogenetics and oligonucleotide array CGH: is this a candidate region for the syndrome? Am. J. Med. Genet. A, 146A, 1886-1889. 